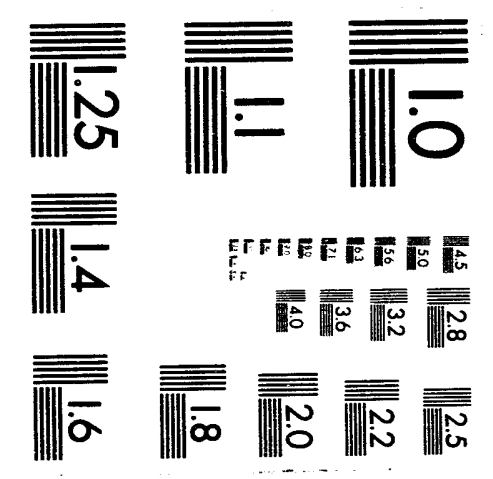



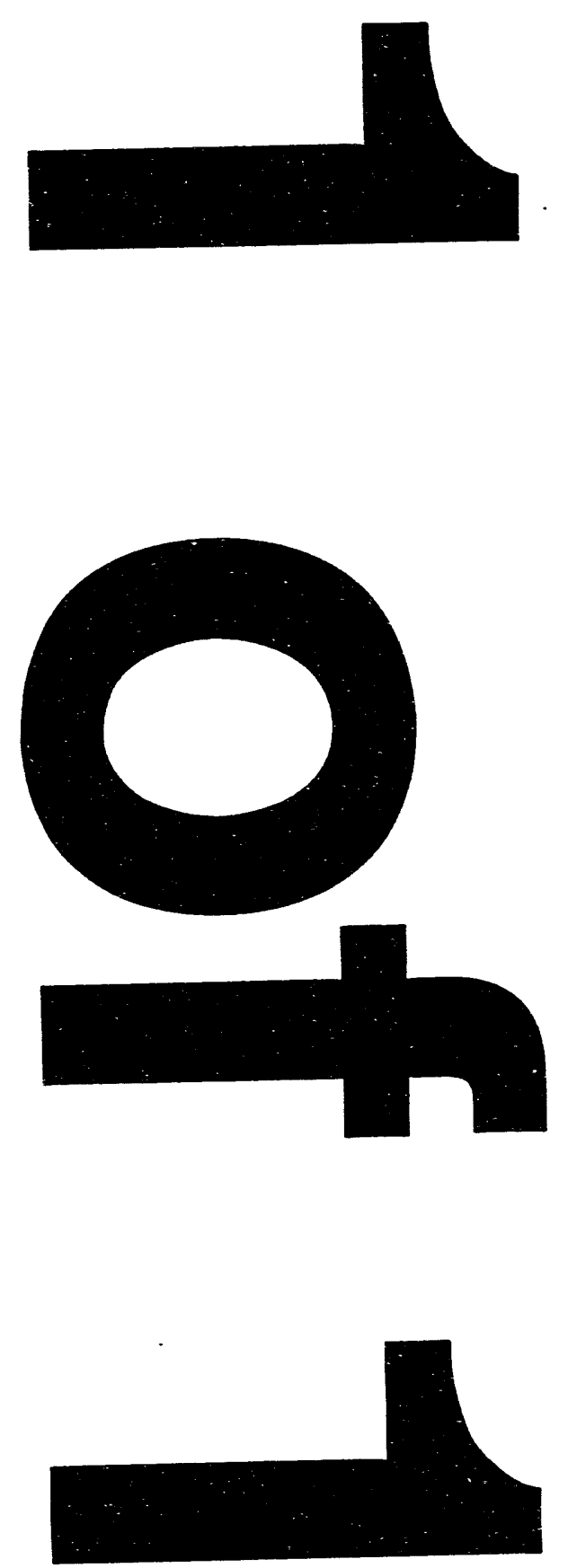


\title{
High Energy Decomposition of Halogenated Hydrocarbons FY93 Final REPORT
}

\author{
B. J. Mincher \\ R. E. Arbon
}

D. H. Meikrantz

Published September 1993

\section{Idaho National Engineering Laboratory EG\&G IDAHO, INC. IDAHO FALLS, IDAHO 83415}

\author{
Prepared for the \\ U. S. Department of Energy \\ Office of Technology Development \\ Under DOE Idaho Field Office \\ Contract DE-AC07-761D01570
}




\section{CONTENTS}

1 INTRODUCTION ..................... 1

2 EXPERIMENTAL METHODS ................... 2

3 RESULTS ...................... 2

3.1 Kinetics ...................... 2

3.2 Scavenger Experiments and Mechanism ........... 3

3.3 Effects of PCB Chlorine Substitution Patterns ........ 6

3.4 Mass Balance . . . . . . . . . . . . . . . 8

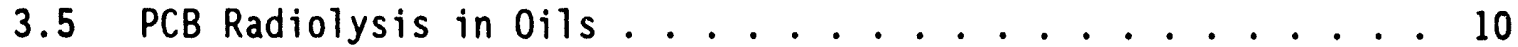

3.6 Catalyst Evaluations ............... 12

3.7 Irradiation of Additional Compounds . . . . . . . . . . . 12

4 TECHNOLOGY TRANSFER POTENTIAL. . . . . . . . . . . . 15

4.1 EPRI . . . . . . . . . . . . . . . . 15

4.2 TVA . . . . . . . . 15

4.3 General Electric Company and McClaren Hart . . . . . . . . . 15

4.4 SalesCo . . . . . . . . . . . . 15

5 CONCLUSIONS AND PROCESS IMPLICATIONS ............. 16

6 PUBLICATIONS AND PRESENTATIONS . . . . . . . . . . . . . . . 17

7 REFERENCES ..................... . . . 19

APPENDIX A: PCB NOMENCLATURE . . . . . . . . . . . . 21

APPENDIX B: MASS BALANCES FOR SELECTED PCB CONGENERS . . . . . . . 22

\section{FIGURES}

1. Dose constant $\left(K_{G}{ }^{-1}\right)$ versus chloro-substitution for selected $\mathrm{PCB}$ congeners. ................... . 6

2. Electron capture chromatographs of Aroclor 1260 before and after irradiation to $175 \mathrm{kGy} . . . . . . . . . . . . .11$

3. A comparison of the radiolysis rates of acenapthylene and acenapthene. . . . . . . . . . . . . . . 14

4. Halothane decomposition versus dose compared to PCB 200. . . . . 14

\section{TABLES}

1. Dose constant $\left(\mathrm{KGy}^{-1}\right)$ for octachlorobiphenyl (PCB 200) in isopropanol under various conditions of irradiation using ATR spent fuel . . . 4 4

2. Dose constant $\left(K G y^{-1}\right)$ for selected PCBs in isopropanol during irradiation with ATR spent fuel. ............ 7

3. Chlorine mass balance for high and low dose constant PCBs. . . . . 8

4. Chlorine mass balance for PCB 200 before and after nitrobenzene addition . . . . . . . . . . . . . . . . 9

5. PAH decomposition dose constants for selected compounds in isopropanol $\left(\mathrm{kGg}^{-1}\right) \ldots \ldots . . \ldots 12$ 


\section{High Energy Decomposition of Halogenated Hydrocarbons FY93 FINAL REPORT}

\section{INTRODUCTION}

This report contains a summary of research findings for FY93 on the program entitled, "High Energy Decomposition of Halogenated Hydrocarbons," (TTP-1D101301). The purpose of this program is to demonstrate a viable process for the decomposition of hazardous organochlorine compounds to nonhazardous products. Early research showed that all tested chlorinated hydrocarbons and many nonhalogenated polyaromatic hydrocarbons were susceptible to decomposition by exposure to gamma radiation, with varying rates. Not surprisingly, the polychlorinated biphenyls (PCBs) were found to be among the most stable (slowest decomposition rate) compounds investigated. Therefore most of the research has focused on that family of compounds, in an effort to design a process with applicability to all chlorinated hydrocarbons.

The process also has applicability to the treatment of mixed wastes containing both chlorinated hydrocarbons and radioactive constituents. The organics may be decomposed leaving only the radioactive constituents in the waste. The process does not radioactively contaminate, or induce radioactivity in, "cold" chlorinated hydrocarbon wastes. Further, the use of spent nuclear fuel as a gamma-ray source presents a potentially cost effective energy source and elegantly allows the fuel to be considered a resource rather than a liability. It has been shown that results generated from spent fuel source studies are applicable to processes using accelerator generated radiation for waste treatment.

Compounds shown to be amenable to the process include PCBs, DDT, lindane, chloroform, trichloroethylene (TCE), and various chlorofluorocarbons (CFCS), as well as some nonhalogenated polyaromatic hydrocarbons (PAHs).

During FY93 more than 400 samples were irradiated with fission product gamma-rays in the spent fuel canal of the ATR. Many of these samples were individual PCB congeners dissolved in isopropanol. There are 209 different congeners in the chemical family known as PCBS. A discussion of their nomenclature can be found in Appendix $A$. These samples were studied to gain an understanding of the mechanism and kinetics of, and to provide a mass balance for, the PCB radiolysis reaction. Since it is known that only a handful of the PCB congeners are actually toxic it was necessary to investigate both toxic and nontoxic congeners and to compare their radiolysis chemistry. Some samples were individual congeners dissolved in oils. This is the matrix in which PCBs are actually encountered in industry, usually in transformers, capacitors, and hydraulic fluids. These samples were used to verify that a similar mechanism for radiolysis occurs in the solutions as they will actually be found in wastes needing to be treated. Finally, some results 
have been obtained for the commercial PCB mixtures known by the trade name Aroclor, also usually found dissolved in oils. Aroclors are mixtures of several dozen congeners present at different concentrations.

In addition to research findings this report also contains a summary of efforts expended on technology transfer, professional publications and conference presentations. The past years' efforts have resulted in two potential private partners interested in PCB decomposition, and the generation of an EPA permit application for a treatability study using PCB containing mixed wastes now in storage at INEL. A patent was applied for covering gamma radiolysis of PCBs in oils. Further, a spin-off from the PCB study involves CFC radiolysis. A patent idea disclosure has been submitted and LDRD funding applied for to study CFC decomposition and transformation.

\section{EXPERIMENTAL METHODS}

The methods used to collect the data discussed in this report are described in the FY92 report EGG-PHY-10466 issued in September 1992, entitled, "High Energy Decomposition of Halogenated Hydrocarbons FY92 Final Report."

It will be noted that radiolysis efficiency in this report is described in terms of the dose constant "d" rather than $G$ values as used previously. The $d$ has units of reciprocal dose and is a dose, rather than time, dependent rate constant. It is calculated as the slope of the linear regression of the natural logarithm of the PCB concentration versus dose curve. Dose constants are preferred to $G$ values due to their independence from starting $P C B$ concentration. Thus the results of one experiment are directly comparable to other experiments. They are also appealing due to their obvious similarities to conventional kinetics rate constants.

\section{RESULTS}

\subsection{Kinetics}

The radiolytic decomposition of PCBs has been shown to exhibit firstorder kinetics. This occurs despite the fact that the reaction is known to be bimolecular, involving reaction of a PCB molecule and one of two radical species produced by solvent radiolysis. The apparent first-order kinetics may be caused by competition for these species by the solvent, which would produce a rate of $P C B$ decomposition independent of the concentration of the species causing decomposition. This is illustrated below:

$$
v=\frac{d_{\mathrm{PCB}}[P C B]\left[e_{\mathrm{sol}}^{-}\right]}{d_{\text {solv }}[\text { solv }]\left[e_{\mathrm{sol}}^{-}\right]}
$$


where $v$ is the rate of PCB decomposition in a solvent, and $d_{P C B}$ is the rate constant for the reaction of PCB with the solvated electron $e^{2}$ sol. The constant $d_{\text {solv }}$ is the rate constant of reaction of the solvent with $e^{-}$sol. The solvated electron is known to be a species causing PCB decomposition. Note that the rate $v$ for PCB decomposition in a solvent which competes for electrons is actually independent of electron concentration, as shown:

$$
v=d^{\prime}[P C B]
$$

The new rate constant $d^{\prime}$ is composed of $d_{P C B}, d_{\text {solv }}$ and [solv], which are all constants.

When the natural logarithm of the PCB concentration is plotted versus absorbed dose a linear relationship occurs. The slope of this line is a dose dependent rate constant hereafter referred to as the dose constant, $d$. All rates of $P C B$ decomposition will be referred to in terms of $d$ which has units of reciprocal dose $\left(\mathrm{KGy}^{-1}\right)$.

\subsection{Scavenger Experiments and Mechanism}

Significant progress was made during FY93 toward an understanding of the mechanism of PCB radiolysis in neutral isopropanol. The use of scavenger experiments was instrumental in determining which reactive species, generated by radiolysis of the isopropanol solvent, are responsible for decomposition of the PCBs.

0xygen is a known free-radical scavenger and some investigators have chosen to perform radiolysis studies in deoxygenated solutions. (1) When we irradiated octachlorobiphenyl (PCB 200) in oxygen-free, nitrogen-sparged, neutral isopropanol no change in the dose constant was observed. The value measured was $0.024 \pm 0.006 \mathrm{kGy}^{-1}$ and is shown in Table 1 . The reactive species causing decomposition is apparently unaffected by the presence of oxygen. This result agrees with those of Sawai(2) although this behavior was used as evidence against a solvated electron initiated mechanism in that study. Our data implicates the solvated electron as one of the principal species involved in PCB decomposition in neutral isopropanol. The fact that deoxygenation is unnecessary has important practical implications for the operation of a PCB radiolysis process.

Experiments were done with other scavengers to investigate their effect on the dose constant for PCB 200 in isopropanol. While such scavenger experiments are common in the radiolys is literature, great care must be taken to choose an electron scavenger which does not have an equally high rate of capture for other radicals and vice versa. Buxton et al. (3) have tabulated rate constants for the reaction of many reagents with electrons, hydrogen atoms, and hydroxyl radicals for aqueous solutions. Reference to these tables allows for the choice of an appropriate scavenger, even in the alcoholic solvents chosen for this study, since only relative reaction rates are of concern. 
Nitrobenzene was added at a concentration of $160 \mathrm{mg} \mathrm{L}^{-1}$ to a solution of octachlorobiphenyl in isopropanol. Nitrobenzene has a diffusion-limited rate constant for reaction with aqueous electrons and its presence in isopropanol suppressed the dose constant by a factor of 2 from $0.024 \pm 0.002$ to $0.013 \pm$ $0.004 \mathrm{kGy}^{-1}$. The same concentration of benzene had no effect on the octachlorobiphenyl dose constant. The rate constant for the reaction of benzene with the aqueous electron is three orders of magnitude less than that of nitrobenzene. These additives have similar reaction rates with hydrogen atoms and hydroxyl radicals. The solvated electron is clearly implicated as an active agent of radiolytic PCB decomposition, however the rate of reaction of nitrobenzene with the isopropanol radical is also known to be high at $2 E 9 \mathrm{~L}$ $\mathrm{mol}^{-1} \mathrm{~s}^{-1} .^{(4)}$ The rate constant for the benzene isopropanol radical reaction is unknown.

Sulfur hexafluoride is also known to have a high rate of reaction with electrons. When sulfur hexafluoride was used as an electron scavenger in saturated irradiated solutions the dose constant was reduced by a factor of 5 to $0.005 \pm 0.001 \mathrm{kGy}^{-1}$. This unambiguously demonstrates participation of the solvated electron as a principal agent of reductive dechlorination of PCB.

Nitrous oxide is also an electron scavenger, with a rate constant of approximately $1 \mathrm{Eg} \mathrm{L} \mathrm{mol}^{-1} \mathrm{~s}^{-1}$. Addition to saturation of nitrous oxide effectively converts the electrons into isopropanol radicals ${ }^{(5)}$ via the following equations.

$$
\begin{gathered}
\mathrm{N}_{2} \mathrm{O}+\mathrm{e}_{\text {sol }}^{-} \rightarrow \mathrm{N}_{2}+0^{-} \\
0^{-}+\left(\mathrm{CH}_{3}\right)_{2} \mathrm{CHOH} \rightarrow\left(\mathrm{CH}_{3}\right)_{2} \dot{\mathrm{COH}}+\mathrm{OH}^{-}
\end{gathered}
$$

When samples of PCB 200 were sparged with nitrous oxide prior to irradiation the dose constant was suppressed by a factor of 2 from $0.024 \pm 0.002$ to 0.011 $\pm 0.005 \mathrm{kGy}^{-1}$. Thus, in the absence of solvated electrons some dechlorination still occurs, presumably by electron transfer from the isopropanol radical. The results of the scavenger experiments discussed above are summarized in Table 1.

Table 1. Dose constant $\left(\mathrm{KGy}^{-1}\right)$ for octachlorobiphenyl (PCB 200) in isopropanol under various conditions of irradiation using ATR spent fuel.

Dose Constant

$0.024 \pm 0.002$

$0.024 \pm 0.006$

$0.023 \pm 0.005$

$0.013 \pm 0.004$

$0.005 \pm 0.001$

$0.011 \pm 0.005$

\section{Condition}

Unadulterated

Deoxygenated

$160 \mathrm{mg} L^{-1}$ Benzene

$160 \mathrm{mg} \mathrm{L}^{-1}$ Nitrobenzene

Sulfur hexafluoride sparge

Nitrous oxide sparge 
A mechanism for the radiolytic decomposition of PCBs in neutral isopropanol, based upon these scavenger experiment results, may be proposed. The solvated electron and the isopropanol radical are generated by direct radiolysis of the solvent, as shown below:

$$
\begin{gathered}
\left(\mathrm{CH}_{3}\right)_{2} \mathrm{CHOH}+\gamma \rightarrow\left[\left(\mathrm{CH}_{3}\right)_{2} \mathrm{CHOH}\right]^{*} \\
{\left[\left(\mathrm{CH}_{3}\right)_{2} \mathrm{CHOH}\right]^{*} \rightarrow \mathrm{e}^{-}{ }_{\mathrm{sol}}+\left[\left(\mathrm{CH}_{3}\right)_{2} \mathrm{CHOH}\right]^{+}} \\
{\left[\left(\mathrm{CH}_{3}\right)_{2} \mathrm{CHOH}\right]^{+} \rightarrow\left(\mathrm{CH}_{3}\right)_{2} \dot{\mathrm{COH}}+\mathrm{H}^{+}}
\end{gathered}
$$

The solvated electron is responsible for about $80 \%$ of the PCB decomposition observed, and acts by reductive dechlorination of the $P C B$, as shown below for octachiorobiphenyl:

$$
\mathrm{e}^{-}+\mathrm{C}_{12} \mathrm{H}_{2} \mathrm{Cl}_{8} \rightarrow \dot{\mathrm{C}}_{12} \mathrm{H}_{2} \mathrm{Cl}_{7}+\mathrm{Cl}^{-}
$$

The dechlorination of the octachlorobipheny1 PCB 200 proceeds with a dose constant of $0.024 \mathrm{kGy}^{-1}$. The dechlorinated heptachlorobiphenyl radical produced then stabilizes by abstraction of a proton from the solvent:

$$
\dot{\mathrm{C}}_{12} \mathrm{H}_{2} \mathrm{Cl}_{7}+\left(\mathrm{CH}_{3}\right)_{2} \mathrm{CHOH} \rightarrow \mathrm{C}_{12} \mathrm{H}_{3} \mathrm{Cl}_{7}+\left(\mathrm{CH}_{3}\right)_{2} \dot{\mathrm{COH}}
$$

Some reductive dechlorination (about $20 \%$ ) occurs due to the isopropanol radical, also a product of isopropanol radiolysis:

$$
\left(\mathrm{CH}_{3}\right)_{2} \dot{\mathrm{COH}}+\mathrm{C}_{12} \mathrm{H}_{2} \mathrm{Cl}_{8} \rightarrow \dot{\mathrm{C}}_{12} \mathrm{H}_{2} \mathrm{Cl}_{7}+\left(\mathrm{CH}_{3}\right)_{2} \mathrm{CO}+\mathrm{HCl}
$$

Regardless of the dechlorination pathway the resulting products of PCB decomposition are the next less chlorinated homologue and free chloride ion. Dechlorination of lower homologues continues in the solution during irradiation until nonchlorinated biphenyl is reached. Biphenyl is also susceptible to reduction via introduction of saturation into the phenyl rings, a) though the dose constants for these reactions are low. Non-aromatic derivatives of $P C B$, presumably produced by electron capture, have been detected in some irradiated solutions. Similar biphenyl derivatives have been reported in solutions of PCBs which have been electrolytically reduced.(6)

A new family of compounds detectable by GCMS has been discovered in some irradiated PCB solutions which results from the addition of isopropanol radicals to the $P C B$ radicals produced during dechlorination. (7) These PCB isopropanol adducts may be produced by the reaction:

$$
\dot{\mathrm{C}}_{12} \mathrm{H}_{2} \mathrm{Cl}_{7}+\left(\mathrm{CH}_{3}\right)_{2} \dot{\mathrm{COH}} \rightarrow \mathrm{C}_{12} \mathrm{H}_{2} \mathrm{Cl}_{7}\left[\left(\mathrm{CH}_{3}\right)_{2} \mathrm{COH}\right]
$$

The formation of these adducts is suppressed by the presence of nitrobenzene (an isopropanol radical scavenger) and enhanced by the presence of nitrous oxide (which generates isopropanol radicals from solvated electrons). A11 PCB 
congeners investigated add isopropanol radicals to greater or lesser extents. This pathway is responsible for a significant, but unquantified amount of PCB decomposition for some congeners. It has been shown that the adducts are also susceptible to radiolytic decomposition.

\subsection{Effects of PCB Chlorine Substitution Patterns}

A further confirmation that solvated electrons are largely responsible for reductive dechlorination of PCBs is the observation that the dose constants measured for various congeners is in qualitative agreement with their response factors by electron capture detection in the gas phase. In general, dose constant increases with increasing chloro-substitution. However, the dose constant is al so dependent upon the substitution pattern within a homologue series. Figure 1 shows a plot of dose constant versus chloro-substitution for selected PCBs in isopropanol. Table 2 shows the dose constants measured for selected PCBs in isopropanol.

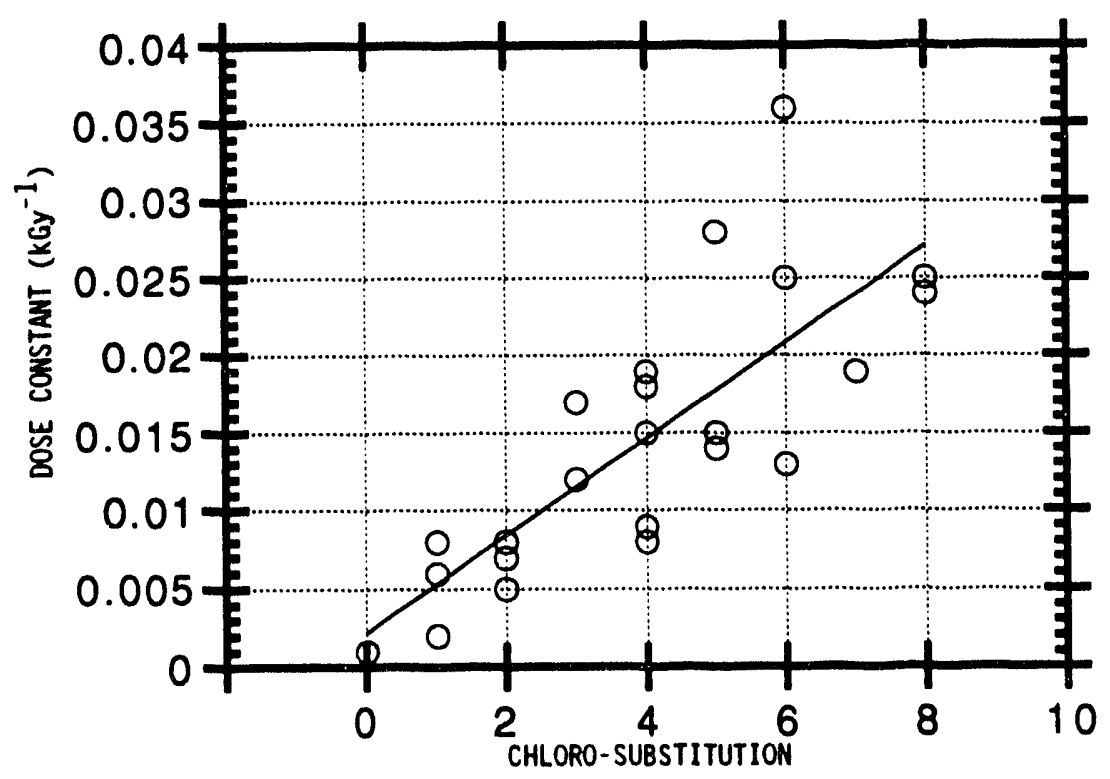

FIGURE 1. Dose constant $\left(K G y^{-1}\right)$ versus chloro-substitution for selected PCB congeners. 
Table 2. Dose constant $\left(\mathrm{KGy}^{-1}\right)$ for selected PCBs* in isopropanol during irradiation with ATR spent fuel.

\begin{tabular}{|c|c|c|}
\hline $\begin{array}{c}\text { PCB \# } \\
1 \\
2 \\
3\end{array}$ & $\begin{array}{c}\begin{array}{c}\text { Substitution } \\
\text { Pattern }\end{array} \\
\text { Biphenyl } \\
2 \\
3 \\
4\end{array}$ & $\begin{array}{l}\text { Dose Constant } \\
0.001 \\
0.006 \pm 0.001 \\
0.002 \pm 0.002 \\
0.008 \pm 0.002\end{array}$ \\
\hline $\begin{array}{r}4 \\
6 \\
11\end{array}$ & $\begin{array}{l}2,2^{\prime} \\
2,3^{\prime} \\
3,3^{\prime}\end{array}$ & $\begin{array}{l}0.008 \pm 0.001 \\
0.007 \pm 0.002 \\
0.005 \pm 0.001\end{array}$ \\
\hline $\begin{array}{l}33 \\
35\end{array}$ & $\begin{array}{l}2^{\prime}, 3,4 \\
3,3^{\prime}, 4\end{array}$ & $\begin{array}{l}0.012 \pm 0.003 \\
0.017 \pm 0.001\end{array}$ \\
\hline $\begin{array}{l}54 \\
60 \\
70 \\
77 \\
81\end{array}$ & $\begin{array}{l}2,2^{\prime}, 6,6^{\prime} \\
2,3,4^{\prime}, 4^{\prime} \\
2,3^{\prime}, 4^{\prime}, 5 \\
3,3^{\prime}, 4,4^{\prime} \\
3,4,4^{\prime}, 5\end{array}$ & $\begin{array}{l}0.008 \pm 0.001 \\
0.009 \pm 0.001 \\
0.015 \pm 0.003 \\
0.019 \pm 0.002 \\
0.018 \pm 0.004\end{array}$ \\
\hline $\begin{array}{l}101 \\
118 \\
126\end{array}$ & $\begin{array}{l}2,2^{\prime} 4,5,5^{\prime} \\
2,3^{\prime}, 4,4^{\prime}, 5 \\
3,3^{\prime}, 4,4^{\prime}, 5\end{array}$ & $\begin{array}{l}0.014 \pm 0.002 \\
0.015 \pm 0.002 \\
0.028 \pm 0.003\end{array}$ \\
\hline $\begin{array}{l}155 \\
167 \\
169\end{array}$ & $\begin{array}{l}2,2^{\prime}, 4,4^{\prime}, 6,6^{\prime} \\
2,3^{\prime}, 4,4^{\prime}, 5,5^{\prime} \\
3,3^{\prime}, 4,4^{\prime}, 5,5^{\prime}\end{array}$ & $\begin{array}{l}0.013 \pm 0.002 \\
0.025 \pm 0.002 \\
0.036 \pm 0.004\end{array}$ \\
\hline 183 & $2,2^{\prime}, 3,4,4^{\prime}, 5^{\prime}, 6$ & $0.019 \pm 0.002$ \\
\hline $\begin{array}{l}194 \\
200\end{array}$ & $\begin{array}{l}2,2^{\prime}, 3,3^{\prime}, 4,4^{\prime}, 5,5^{\prime} \\
2,2^{\prime}, 3,3^{\prime}, 4,5^{\prime}, 6,6^{\prime}\end{array}$ & $\begin{array}{l}0.025 \pm 0.002 \\
0.024 \pm 0.002\end{array}$ \\
\hline
\end{tabular}

Reference to dose constants within a given homologue series in Table 2 reveals that chloro-substitution in the 3 position (meta-substitution) results in higher dose constants. These congeners also generate higher concentrations of solvent adducts. Conversely, substitution in the 2 position (orthosubstitution) results in a lower dose constant, and very small amounts of adduct formation. This is a fortuitous result because those PCBs which are responsible for the toxicity of $P C B$ mixtures are the non-ortho substituted 
congeners. ${ }^{(8)}$ Thus, the shift in the congener mix during irradiation is toward lower total chlorine substitution with more rapid decomposition of the most toxic congeners. The most toxic congener is PCB 126. (8) This PCB has one of the highest dose constants measured in our system. Congener 118 is the most toxic congener with a wide environmental distribution and it also has a high radiolysis dose constant. Thus, radiolysis of PCB mixtures results in a lightly chlorinated, non-toxic product, even if radiolysis is not carried to completion. The lightly chlorinated congeners are also more susceptible to microbial degradation in an environmental setting.

\subsection{Mass Balance}

The mass balance calculations for PCB radiolysis in neutral isopropanol are complicated by the fact that to some extent each of the 209 PCB congeners observes its own chemistry in this system. This is due to the effect of varying chloro-substitution on dose constant and susceptibility to solvent adduct formation. In general, those congeners having low dose constants provide good mass balances, in the range of $100 \%$. An example is PCB 101, with $d=0.014 \mathrm{kGy}^{-1}$, a low dose constant for the pentachlorobiphenyl homologue series. The mass balance for chlorine over a range of doses is shown in Table 3.

Table 3. Chlorine mass balance for high and low dose constant PCBs.

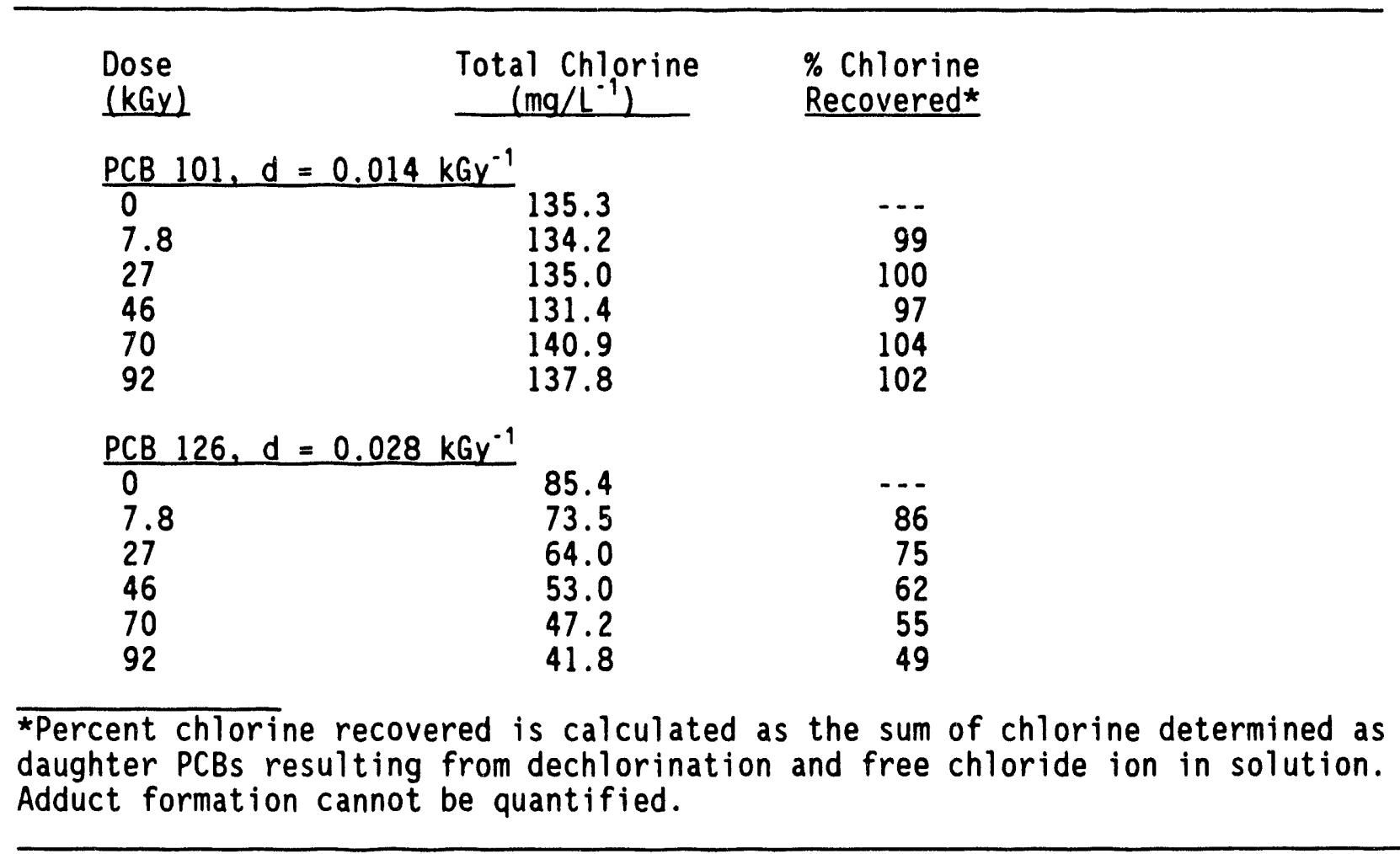


Al so shown in Table 3 is the chlorine recovery for PCB 126, a pentachlorobiphenyl with a dose constant two times higher than PCB 101. The mass balance becomes progressively worse with dose. Similar results were previously reported for PCB 200. (10) For PCB 200 it has been demonstrated that the PCB-solvent adduct accounts for the missing chlorine. This was accomplished via scavenging of the isopropanol radical with nitrobenzene, which suppresses adduct formation. Table 4 shows chlorine recoveries for PCB 200 after absorbing about $100 \mathrm{kGy}$ in the presence and absence of nitrobenzene.

Table 4. Chlorine mass balance for PCB 200 before and after nitrobenzene addition.

\begin{tabular}{|c|c|c|}
\hline $\begin{array}{l}\text { Dose } \\
\text { (kGy) }\end{array}$ & $\begin{array}{c}\text { Total Chlorine } \\
\left(\mathrm{mg} / \mathrm{L}^{-1}\right)\end{array}$ & $\begin{array}{l}\% \text { Chlorine } \\
\text { Recovery }\end{array}$ \\
\hline$\frac{P C B \quad 20}{0}$ & $G y^{-1}$ & 55 \\
\hline $\begin{array}{l}\frac{P C B \quad 20}{0} \\
109\end{array}$ & $\begin{array}{r}\text { nzene } \\
109 \\
100\end{array}$ & 97 \\
\hline
\end{tabular}

Thus, for PCB 200 the presence of adducts accounts for the completion of the chlorine mass balance. This may not be the case for all congeners. Recent work at Montana State University has detected what is probably a new class of compounds resulting from PCB radiolysis using liquid chromatography/mass spectrometry (LCMS). Al1 that is currently known about these compounds is that they are very polar and that they absorb in the same ultraviolet region as compounds containing phenyl rings. These species may account for the mass still missing when some congeners are irradiated. Chloride and carbon recovery data for congeners investigated to date are shown in Appendix B.

The radiolysis of PCBs in isopropanol does not result in the generation of semivolatile organochlorines other than those discussed. Previously, samples were analyzed for organochlorine volatile compounds (VOC) and none were detected. A replicate series of irradiations performed in FY93 confirmed the absence of volatile organochlorines in the radiolysis products. Chlorine gas has also not been detected in irradiated samples. Currently, toxicity testing studies have begun to compare the pre-, and post-irradiation toxicity of PCB samples. 


\subsection{PCB Radiolysis in 0ils}

The octachlorobiphenyl PCB 200 has been irradiated at the ATR in Shell Diala A transformer oil and has been found to have a dose constant of $0.019 \pm$ $0.009 \mathrm{kGy}^{-1}$. This value is about $80 \%$ of the decomposition rate in neutral isopropanol. A slower rate is consistent with the absence of isopropanol radicals. Irradiation at the LLNL $9 \mathrm{MeV}$ Linatron Accelerator produces a slightly higher dose constant of $0.022 \pm 0.003 \mathrm{kGy}^{-1}$, consistent with results in isopropanol. When molar amounts of carbon tetrachloride were added the decomposition of PCBs was completely suppressed, probably due to electron capture by the overwhelming amounts of that scavenger. This was previously reported. ${ }^{(10)}$

A commercial PCB mixture of the trade name Aroclor 1260 was irradiated in transformer $0 \mathrm{il}$ and found to have a dose constant of $0.003 \pm 0.002 \mathrm{kGy}^{-1}$. This value is approximately one-seventh that of octachlorobiphenyl due to the ingrowth of daughter $P C B$ congeners being included in the $P C B$ mixture quantification. (When measuring individual PCB dose constants the daughters were not added to the total and thus dose constants appear to be higher.) When the experiment was repeated in hydraul ic oil a constant of $0.005 \pm 0.003$ $\mathrm{kGy}^{-1}$ was obtained.

Figure 2 shows electron capture chromatographs of Aroclor 1260 peaks before and after irradiation in hydraulic oil to $175 \mathrm{kGy}$. The overall decrease in total Aroclor peaks and a shift to lower chlorination (shorter retention times) is apparent. Hydraulic oils are of especial interest at INEL where PCB-containing mixed wastes in a hydraulic oil matrix are in storage with no identified treatment option. A TSCA permit application to perform a treatability study using radiolysis on this waste is presently under review at the DOE-ID field office prior to submission to EPA.

Currently, PCB 54 and PCB 77 are undergoing irradiation in transformer oil. Both congeners are tetrachlorobiphenyls, the first with a low dose constant in isopropanol, the second with a high dose constant. Additionally, a second sample of PCB 77 has been sparged with sulfur hexafluoride and is being irradiated. If these results are consistent with those obtained in isopropanol then the solvated electron will be implicated as the active agent of decomposition in oils as well. It is not expected that solvent radicals will play an important role in the decomposition of PCBs in oils, thus the absence of solvent PCB adducts should simplify mass balance measurements. 

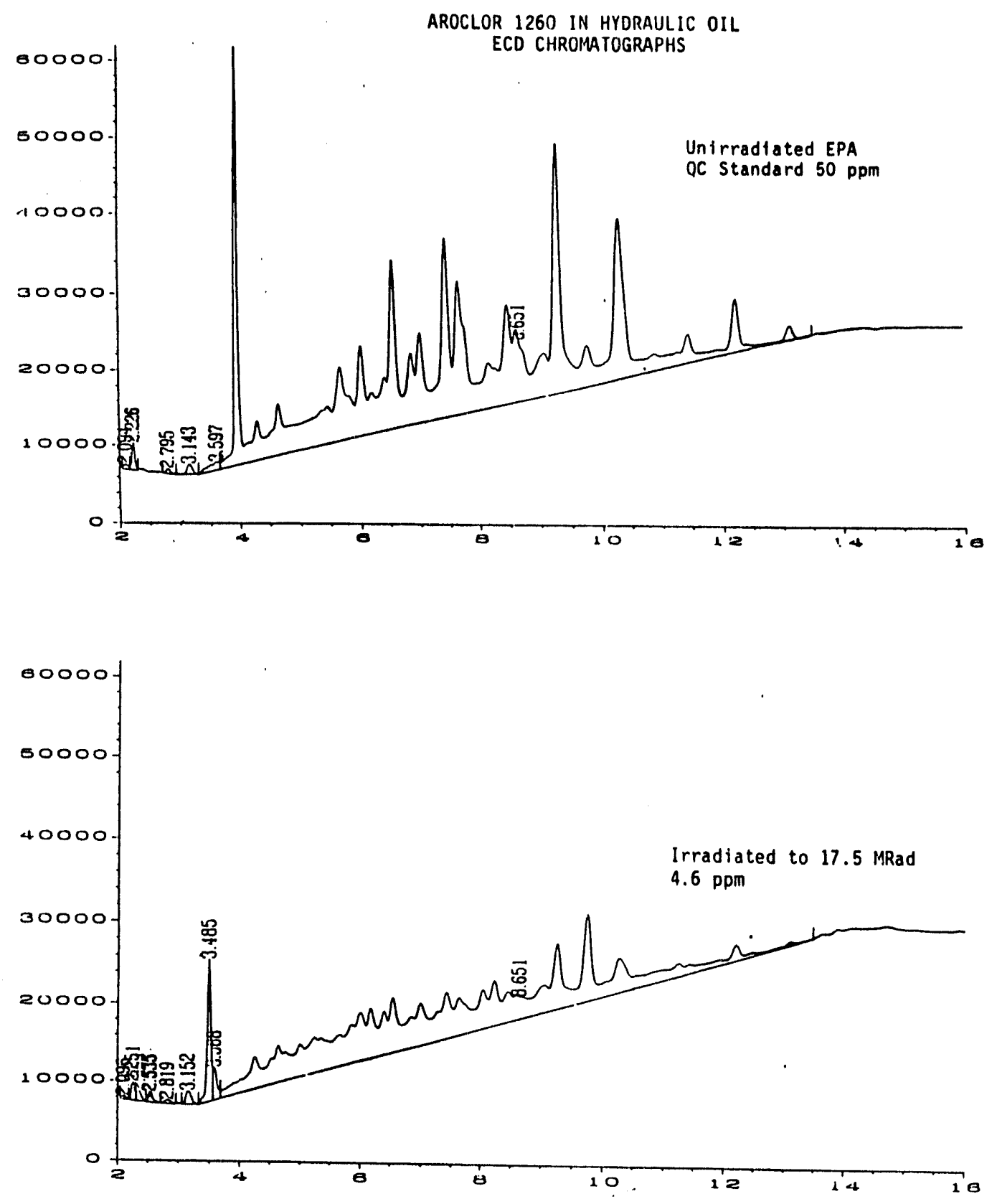

Figure 2. Electron capture chromatographs of Aroclor 1260 before and after irradiation to $175 \mathrm{kGy}$. 


\subsection{Catalyst Evaluations}

Previously we reported that the $\mathrm{Zn} / \mathrm{Cu}$ couple dehalogenation catalyst ${ }^{(11)}$ and hydrogen peroxide ${ }^{(10)}$ do not increase radiolysis efficiency. Recently, a number of potential catalysts were selected based upon an improved understanding of the mechanism of PCB radiolysis. The only one showing promise when added to isopropanol was potassium hydroxide. Compounds tested but shown not to improve reaction efficiency were silver nitrate, sodium bicarbonate and sodium nitrate and triethylamine. Although potassium hydroxide improves reaction efficiency in isopropanol it does so by increasing the population of isopropanol radical anions. This phenomena is well reported in the literature. ${ }^{(2,5)}$ However, potassium hydroxide is not expected to improve decomposition efficiency in oils.

\subsection{Irradiation of Additional Compounds}

A number of experiments have been performed to assess the potential for adoption of this process to the treatment of other organic compounds. Based upon our previous work, the pesticides DDT and lindane, (12) and solvents such as carbon tetrachloride, chloroform and trichloroethylene may be decomposed at doses much lower than that required for PCBs. More recently a series of irradiations of a mixture of polyaromatic hydrocarbons (PAH) was performed in isopropanol. The dose constants measured are shown in Table 5 . It can be seen that some PAHs were susceptible to attack, while others of similar structure were not. We believe that these dose constants are primarily related to the electron capture rates for these compounds. This is especially suggested in Figure 3 where acenapthylene is compared to acenapthene. The presence of a double bond in acenapthylene not stabilized by resonance may be the site of reductive attack by the solvated electron.

Table 5. PAH decomposition dose constants for selected compounds in isopropanol $\left(\mathrm{KGy}^{-1}\right)$.

\begin{tabular}{ll}
\multicolumn{1}{c}{ Compound } & $\frac{d}{\text { Naphthalene }}$ \\
Acenapthylene & 0.081 \\
Acenapthene & stable \\
Fluorene & stable \\
Phenanthrene & stable \\
Anthracene & 0.064 \\
Fluoranthene & 0.019 \\
Pyrene & 0.011 \\
Benzo(a)anthracene & 0.041 \\
Chrysene & 0.004 \\
Benzo(a)pyrene & 0.019 \\
Benzo(g,h,i)perylene & 0.013
\end{tabular}


Finally, the chlorofluorocarbon compound (CFC) halothane (trifluoro-2chloro-2 bromoethane) was irradiated in isopropanol. Halothane is representative of CFCS and halons now being phased out of use worldwide under the Montreal Protocol. The phase out is due to their ozone depletion behavior in the upper atmosphere. As expected for an electron capture reaction on such a compound the bromines and chlorines were removed while the fluorines remained attached to the hydrocarbon. Fluorocarbons are not ozone active and are in fact being considered for use as CFC substitutes in industry. Figure 4 shows a curve of halothane destruction versus dose with a curve of PCB 200 destruction for comparison. The figure shows quantitative halothane decomposition after only $10 \mathrm{kGy}^{-1}$. 


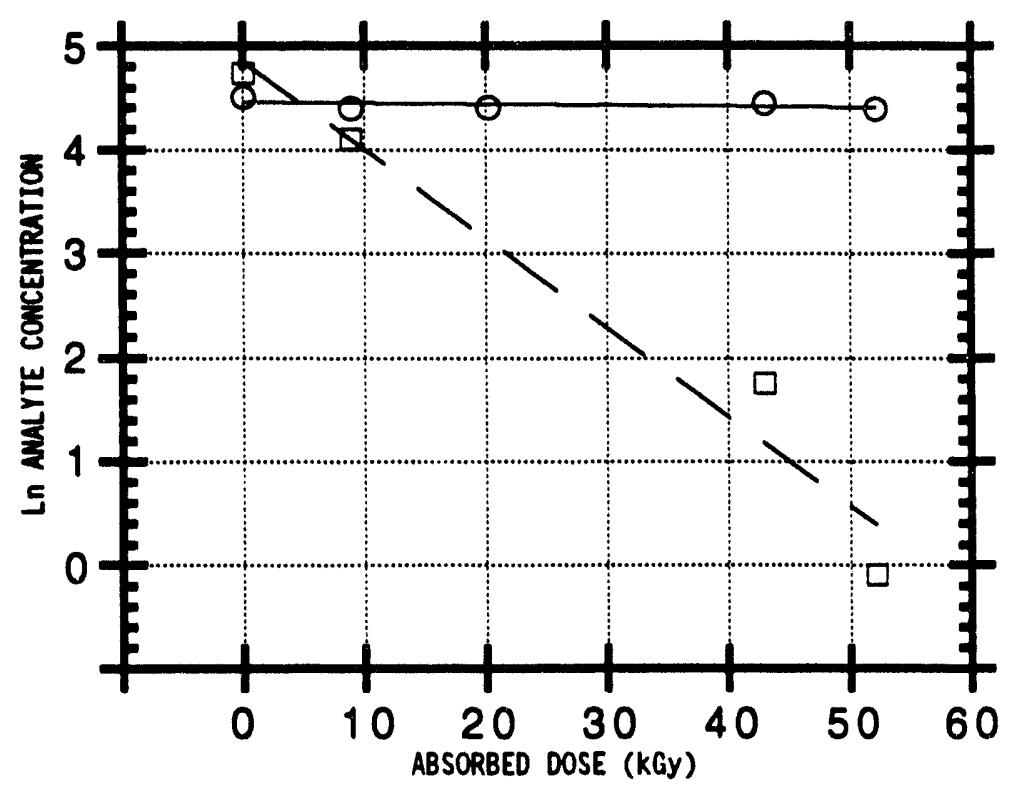

FIGURE 3. A comparison of the radiolys is rates of acenapthylene and acenapthene.

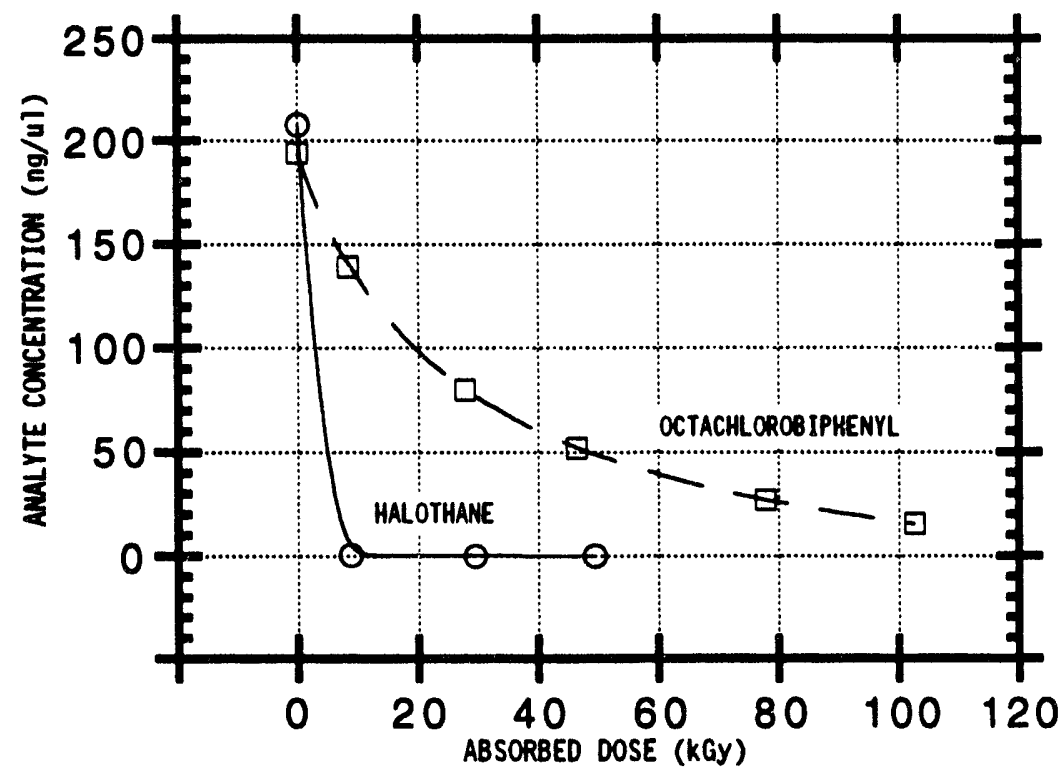

FIGURE 4. Halothane decomposition versus dose compared to PCB 200. 


\section{TECHNOLOGY TRANSFER POTENTIAL}

Several commercial entities with an interest in high energy decomposition PCB disposal-based processes were identified and contacted during FY93. Among them were EPRI, TVA, General Electric, McClaren Hart Environmental Engineering and SalesCo.

\subsection{EPRI}

Although our paper was well received at the EPRI sponsored Advanced Oxidation Technology Conference in February, the initial enthusiasm has since been lost. Conversations with Myron Jones and Dr. Babu Nott of the Environment and Energy Management Office of EPRI expressed a concern that the DOE bureaucracy may prevent successful collaboration.

\subsection{TVA}

The TVA has had representatives at the Florida Environmental Chemistry Conference for the past two years and will most likely continue to attend. Although they also expressed initial enthusiasm their interest has waned, possibily due to decreased budgets and personnel reorganizations.

\subsection{General Electric Company and McClaren Hart}

Research results were presented to Dr. Daniel Abramowiscz, Dr. Richard Sheldon and other technical staff at the GE Corporate R\&D lab in Schenectady, NY in June. Dr. Abramowiscz was originally contacted at the Florida Environmental Chemistry Conference. Dr. Sheldon referred us to Paul LaBonte, Regional Manager of $\mathrm{MCCl}$ aren Hart Environmental Engineering Corporation in Albany. Mr. LaBonte has been involved in establishing CRADAs with DOE sites and industry for similar programs. Mr. LaBonte and Dr. Sheldon are currently investigating the possibility of a three-way collaboration researching the use of radiolysis to treat PCB contaminated Hudson River sludges.

\subsection{Salesco}

Salesco is a private company involved in recycling of fluorescent light ballasts. Ballasts containing PCBs reprent a major waste management expense for both industry and government. An estimated 5 billion ballasts currently await disposal at a cost of \$4-\$8 each. Salesco has expressed interest to the EG\&G ORTA office in helping fund a demonstration of radiolysis treatment of fluorescent light ballasts containing PCBs. 


\section{CONCLUSIONS AND PROCESS IMPLICATIONS}

The major features of the mechanism of PCB radiolysis are now understood. The principal agents of decomposition in isopropanol are the solvated electron and the isopropanol radical. Both species cause reductive dechlorination of PCBs and are generated by direct radiolys is of the solvent. The kinetics of the $P C B$ radical reaction are either first-order, or pseudo first-order and may be described by a dose dependent rate constant $d$. The main reaction is reductive dechlorination, although addition reactions of isopropanol radicals to PCB daughters have been observed. The importance of these three main routes of decomposition varies with the congener of interest. The pattern and level of chloro-substitution may be used to determine whether $d$ will be relatively high or low and whether adduct formation will occur.

Chlorine mass balances have been worked out for 22 congeners. For some low d congeners, which do not form adducts, one hundred percent balance is obtained when PCB chlorine and free chloride ion are summed in post-

irradiation material. In some high d adduct-forming congener solutions it has been observed that adduct chlorine completes, or nearly completes the mass balance. However, since each of the 209 congeners apparently observes somewhat unique chemistry new techniques are still being investigated to search for unknown reaction products. While the possibility that undiscovered products exist is small, they have important implications for using radiolysis as a process waste treatment. EPA approved methods have been employed which indicate that no regulated by-products are being formed by this radiolysis process. Toxicity studies are currently being performed on irradiated PCB solutions.

The decomposition of PCBs in transformer and hydraulic oils proceeds with a lower first-order d, probably due to the lower dielectric constant of oils and the absence of solvent radical participation. The doses required for any given level of decontamination may be predicted from experimentally determined dose constants, and are easily achievable. The principal mode of decomposition also appears to be by solvated electron initiated reduction. The formation of solvent adducts is not anticipated in oils and as such, dechlorination to biphenyl, reduced biphenyl derivatives, and chloride ion may be stoichiometric. Thus the organic products of PCB radiolysis should be very similar to the oil itself. This is especially true for transformer oils, which all have high aromatic hydrocarbon content.

When commercial PCB mixtures such as Aroclor 1260 are irradiated, the ratio of congeners is shifted toward lightly chlorinated, non-toxic congeners. Continued irradiation results in oil solutions in which PCB levels are reduced to below the detection limit using EPA analytical protocols. Thus a process is possible in which PCB containing oils may be irradiated in-situ in transformers or light ballasts using a dose which may be calculated based upon known rate constants. Irradiation would continue to a predetermined level of 
decontamination. Cutting and draining of containers or use of additives would not be required. The product would contain non-toxic organic compounds similar in nature to the oil matrix, and chloride ion.

A potential commercial collaborator has suggested that this process may be especially amenable to treatment of PCB containing fluorescent light ballasts. Approximately 2.5 billion ballasts are said to be owned by private industry with another 2.5 billion owned by the federal government. The current cost for treatment of these ballasts ranges from $\$ 4$ to $\$ 8$ each. Gamma-ray irradiation is a potentially far cheaper treatment alternative, for which costs will be governed solely by regulatory requirements.

The demonstration that radiolysis is useful on many organic compounds, including some nonchlorinated PAHs is of interest. All other susceptible compounds examined have dose constants much higher than those of PCBs. The fact that CFCs are readily decomposed to fluorocarbons, at very high rates, suggests that radiolysis may be useful for destroying stockpiles of stored halons and other CFCs now being phased out of use due to atmospheric ozone depletion.

\section{PUBLICATIONS AND PRESENTATIONS}

The following is a list of refereed journal publications generated as a result of this program.

Mincher, B. J., Arbon, R. E., Knighton, W. B., and Meikrantz, D. H., Gamma-ray Induced Degradation of PCBs in Neutral Isopropanol Using Spent Reactor Fuel, submitted to Appl. Radiat. Isot. in May 1993.

Mincher, B. J. and Zaidi, M. K. (1993), Calibration of Far West Technology (FWT-60) Radiachromic Dye Dosemeters, Rad. Prot. Dosimetry.

Mincher, B. J., Meikrantz, D. H., Murphy, R. J., Gresham, G. L., and Connolly, M. J. (1991), Gamma-ray Induced Degradation of PCBs and Pesticides Using Spent Reactor Fuel, Appl. Radiat. Isot. 42, 1061.

Matthews, S. M., Boegel, A. J., Loftis, J. A., Caufield, R. A., Mincher, B. J., Meikrantz, D. H., and Murphy, R. J. (1991), Decomposition of Halogenated Hydrocarbons Using Intense, Penetrating Bremsstrahlung, Radiat. Phys. Chem 42, 689,

Two other manuscripts are currently in preparation. Below is a list of conference presentations which have resulted from this program. Those papers which have been invited are marked with an asterisk.

Knighton, W. B., Sears, L. J., Arbon, R. E., Mincher, B. J., Meikrantz, D. $H$. , Identification of PCB Degradation Products in Gamma-Ray Irradiation Solutions of PCBs in Isopropanol, 41 st ASMS Conference on Mass 
Spectrometry and Allied Topics, May 30-June 4, 1993, San Francisco, CA, USA.

Mincher, B. J., Arbon, R. E., and Meikrantz, D. H., The Radiolytic Decomposition of PCBs in 0i1, Symposium on Environmental Applications of Advanced Oxidation Technologies, February 22-24, 1993, San Francisco, CA, USA.

*Meikrantz, D. H., Mincher, B. J., Arbon, R. E., and Knighton, W. B., PCB Destruction via High Energy Irradiation, Part II, Florida Environmental Chemistry Conference, October 19-22, 1992, Palm Coast, FL, USA.

Matthews, S. M., Boegel, A. J., Loftis, J. A., Caufield, R. A., Mincher, B. J., Meikrantz, D. H., and Murphy, R. G., Decomposition of Halogenated Hydrocarbons Using Intense, Penetrating Bremsstrahlung, 8th International Meeting on Radiation Processing, September 14-19, 1992, Beijing, China.

Arbon, R. E., Mincher, B. J., and Meikrantz, D. H., Gamma Radiolys is of Chlorinated Hydrocarbons, Spectrum '92, Nuclear and Hazardous Waste Management International Topical Meeting, August 23-27, 1992, Boise, ID, USA.

Mincher, B. J., and Zaidi, M. K., Calibration of Far West Technology (FWT-60) Radiachromic Dye Dosemeters, 10th Solid State Dosimetry Conference, July 13-17, 1992, Washington, D.C., USA.

Mincher, B. J., Wells, R. P., and Reilly, H. J., Public Acceptability of the Use of Gamma Rays from Spent Nuclear Fuel as a Hazardous Waste Treatment Process, ANS Embedded Topical Meeting, Risk Management Expanding Horizons, June 8-10, 1992, Boston, MA, USA.

*Mincher, B. J., Meikrantz, D. H., Arbon, R. E., and Murphy, R. J., Gamma-Ray Decomposition of PCBs, Florida Environmental Chemistry Conference, October 30-November 1, 1991, Palm Coast, FL, USA.

Matthews, S. M., Boegel, A. J., Eccles, S. F., Homann, S. G., Rice, D. W., Loftis, J. A., Jovanovich, M. C., Caufield, R. A., Mincher, B. J., Meikrantz, D. H., Murphy, R. J., Gresham, G. L., and Connolly, M. J., High Energy Irradiation of Chlorinated Hydrocarbons, ANS International Topical Conference, MARC-II, April 21-27, 1991, Kona, HI, USA.

In addition, invitations have been received to present papers at the Florida Environmental Chemistry Conference in October 1993, and at the First International Conference on Advanced Oxidation Technologies for Water and Air Remediation in London, Ontario, Canada in June 1994.

This program has helped to sponsor the Florida Environmental Chemistry Conference for the past two years. 


\section{REFERENCES}

1. Evans, R., Nesyto, E., Radlowski, C., and Sherman, W. V. (1971), Mechanisms of the Radiation-Induced Dechlorination of 1,1,1-Trichloro2,2-bis(p-chlorophenyl) Ethane in Alcoholic Solution, J. Phys. Chem. 75, 2762 .

2. Sawai, T., Shimokawa, T., and Shinozaki, Y. (1974), The Radiolytic-Chain Dechlorination of Polychlorinated Biphenyls in Alkaline 2-Propanol

Solutions, Bull. Chem. Soc. Jpn. 47, 1889.

3. Buxton, G. B., Greenstock, C. L., Helman, W. P., and Ross, A. B. (1988), Critical Review of Rate Constants for Reactions of Hydrated Electrons, Hydrogen Atoms and Hydroxyl Radicals $\left(\cdot \mathrm{OH} / \cdot 0^{\circ}\right)$ in Aqueous Solution, $J$. Phys. Chem. Ref. Data 17, 513.

4. Jagannadham, V., and Steenken, S. (1984), One-electron Reduction of Nitrobenzene by $\alpha$-hydroxy Alkyl Radical via Addition/Elimination, An Example of an Organic Inter-sphere Electron-transfer Reaction, J. Am. Chem. Soc. 106, 6542.

5. Sherman, W. V. (1968), Radical-Initiated Chain Dehalogenation of Alkyl Halides in Alkaline Alcoholic Solution, J. Phys. Chem. 72. 2287.

6. Zhang, S., and Rusling, J. F. (1993), Dechlorination of Polychlorinated Biphenyls by Electrochemical Catalysis in a Bicontinuous Microemulsion, Environ. Sci. Technol. 27, 1375.

7. Knighton, W. B., Sears, L. J., Arbon, R. E., Mincher, B. J., and Meikrantz, D. H., Ident ification of PCB Degradation Products in Gamma-Ray Irradiated Solutions of PCBS in Isopropanol, presented at the American Society of Mass Spectrometry Conference, San Francisco, CA, USA, May 1993.

8. DeVoogt, P., Wells, D. E., Reutergardh, L., and Brinkman, V. (1990), Biological Activity, Determination and Occurrence of Planar, Mono-, and Di-ortho PCBs, Intern. J. Environ. Anal. Chem. 40, 1.

9. Abramowiscz, D. A., Brennan, M. J., VanDort, H. M., Gallagher, E. L., (1993), Factors Influencing the Rate of Polychlorinated Biphenyl Dechlorination in Hudson River Sediments, Environ. Sci. Technol. 27, 1125.

10. Mincher, B. J., Arbon, R. E., Meikrantz, D. H., High Energy Decomposition of Halogenated Hydrocarbons FY92 Final Report, (1992), EG\&G Report EGGPHY-10446. 
11. Mincher, B. J., Meikrantz, D. H., Arbon, R. E., Murphy, R. J., High Energy Decomposition of Halogenated Hydrocarbons FY91 Final Report, (1991), EG\&G Report EGG-WTD-9935.

12. Mincher, B. J., Meikrantz, D. H., Murphy, R. J., Gresham, G. L., and Connolly, M. J. (1991), Gamma-ray Induced Degradation of PCBs and Pesticides Using Spent Reactor Fuel, Appl. Radiat. Isot. 42, 1061. 


\section{APPENDIX A}

\section{PCB Nomenclature}

The family of compounds known as PCBs (polychlorinated biphenyls) contain 209 different compounds, called congeners. The congeners vary according to their number and pattern of chloro-substitution. The common feature of nonchlorinated biphenyl and the PCBs is a structure consisting of two phenyl rings joined by a carbon-carbon bond. The positions for chlorine substitution on the phenyl rings are designated as shown:

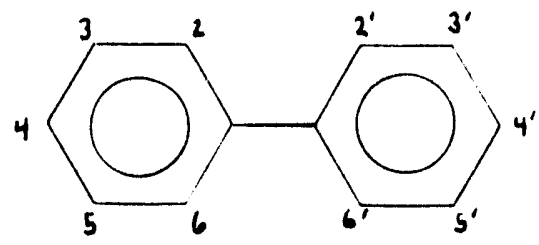

The structure is very stable, and PCBs are inert toward many chemical reactions. This feature has made them useful in industry, but has resulted in difficulty for treatments aimed at PCB destruction. A PCB may be named by designating each chlorine substituted position, followed by a prefix designating the total number of chlorines. For example, 2, 2',6, $6^{\prime}$ tetrachlorobiphenyl has the structure:

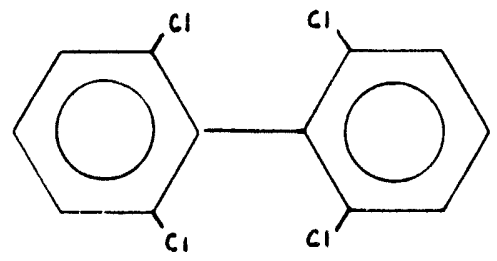

It is also said to be "ortho" substituted and is thus a nontoxic PCB. The 2 and 6 positions are ortho, the 3 and 5 positions are meta and the 4 positions are para. Each of the 209 congeners has also been assigned a number. This is known as the PCB number, or the BZ number (after Ballschmiter and Ze11). The tetrachlorobiphenyl shown above is PCB \#54. Table 2 in section 3.3 of this report shows the PCB numbers and substitution patterns for all congeners examined in this study. 


\section{APPENDIX B}

Mass Balances For Selected PCB Congeners

(Sum of daughter congeners and free chloride, contribution of adducts not shown.)

PCB Number

1

3

6 Dose $\left(\mathrm{kGY}^{-1}\right)$

117

12.5

40.5

125

151

33

35

54

60

77
10.6

31.8

56.6

97.4

10.6

31.8

56.6

97.4

\% Cl Recovered

7.8

27.0

45.9

69.9

91.8

7.8

27.0

45.9

69.9

91.8

7.5

27.9

45.9

77.6

100

7.5

27.9

45.9

77.6

100

7.5

27.9

45.9

77.6

100
102

87

80

75

99

97

95

82

112

98

85

91

\% C Recovered

97

97

92

88

87

99

99

100

95

91

90

90

89

90

99

99

88

78

70

100

98

93

89

86

92

93

95

95

98

102

106

98

95

88

102

105

99

93

87

97

93

89

84

82

103

105

105

96

90

94

81

77

70

65 
PCB Number

81

101

118

126

155

167

169

183

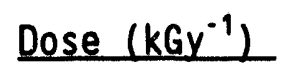

7.5

27.9

45.9

77.6

100

7.8

27.0

45.9

69.9

91.8

7.8

27.0

45.9

69.9

91.8

7.8

27.0

45.9

69.9

91.8

7.5

27.9

45.9

77.6

100

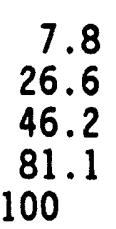

7.8

26.6

46.2

81.1

100

7.8

27.0

45.9

69.9

91.8
\% Cl Recovered

82

80

68

73

72

99

100

97

104

102

102

99

98

88

90

86

75

62

55

49

97

95

98

84

92

96

89

87

75

70

94

73

$--$

56

101

101

99

97

97
\% C Recovered

81

77

63

65

69

98

96

99

97

95

102

96

92

83

83

91

86

73

68

59

97

93

95

89

84

96

92

91

90

74

95

83

75

63

57

101

97

94

87

85 
PCB Number 194

\begin{tabular}{c} 
Dose $\left(\mathrm{kGy}^{-1}\right)$ \\
\hline 7.8 \\
27.0 \\
45.9 \\
69.9 \\
91.8
\end{tabular}

200
8.3

27.7

46.4

77.8

103
$\%$ Cl Recovered

92

92

--

97

$\%$ C Recovered 86

66

62
81

70

63

56

55 

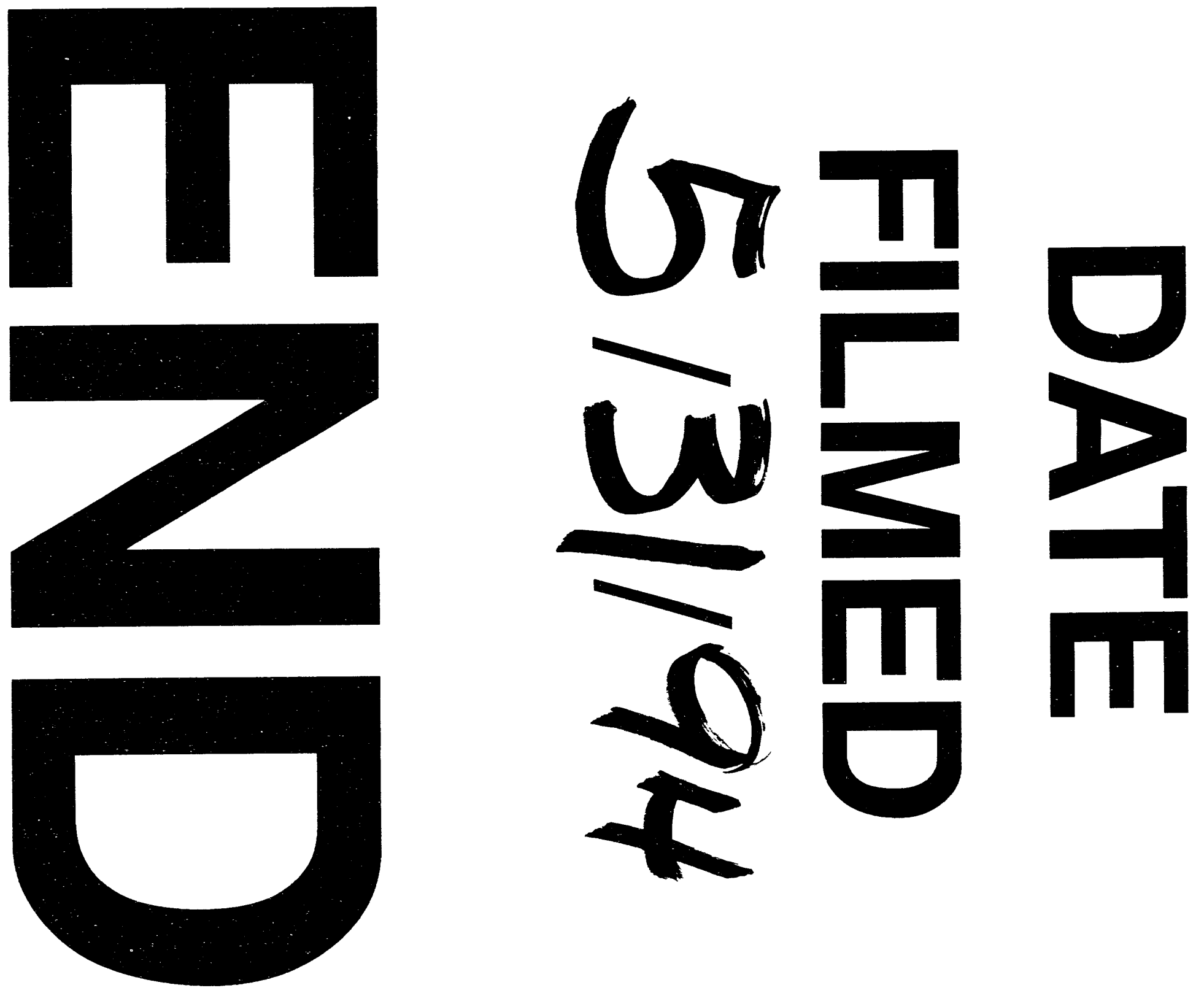
